\title{
Erratum
}

\section{The desert at Zait Bay, Egypt: a bird migration bottleneck of global importance - ERRATUM}

\author{
GUDRUN HILGERLOH
}

doi:10.1017/S0959270909008430. Bird Conservation International (2009) 19:338-352

The paper published by Hilgerloh (2009) proposed certain amendments to the boundaries of Gebel El Zeit (EGo31), an Important Bird Area (IBA) in Egypt. These proposals were based on digital information supplied by the BirdLife International Secretariat during the preparation of the paper. However, subsequent correspondence with Sherif Baha El Din, who first proposed the IBA, has shown that the proposed amendments in fact coincide with his original conception of the site (Baha El Din 1999, 2001). However, digitisation of the IBA boundaries did not take place until some years after the inventory had been compiled, at which time an error was made for this site which has remained unnoticed until now. The BirdLife International Secretariat assumes full responsibility for this error and apologises to all concerned. The correct map for the IBA appears as Figure 1.

\section{References}

Baha El Din, S. (1999) Directory of Important Bird Areas in Egypt. Dokki, Cairo: Privately published.

Baha El Din, S. (2001) Egypt. Pp.241-264. in L. D. C. Fishpool and M. I. Evans, eds. Important Bird Areas in Africa and associated islands: Priority sites for conservation.
Newbury and Cambridge, UK: Pisces publications and BirdLife International. (BirdLife Conservation Series no. 11).

Hilgerloh, G. (2009) The desert at Zait Bay, Egypt: a bird migration bottleneck of global importance. Bird Conserv. Int. 19: 338-352. 


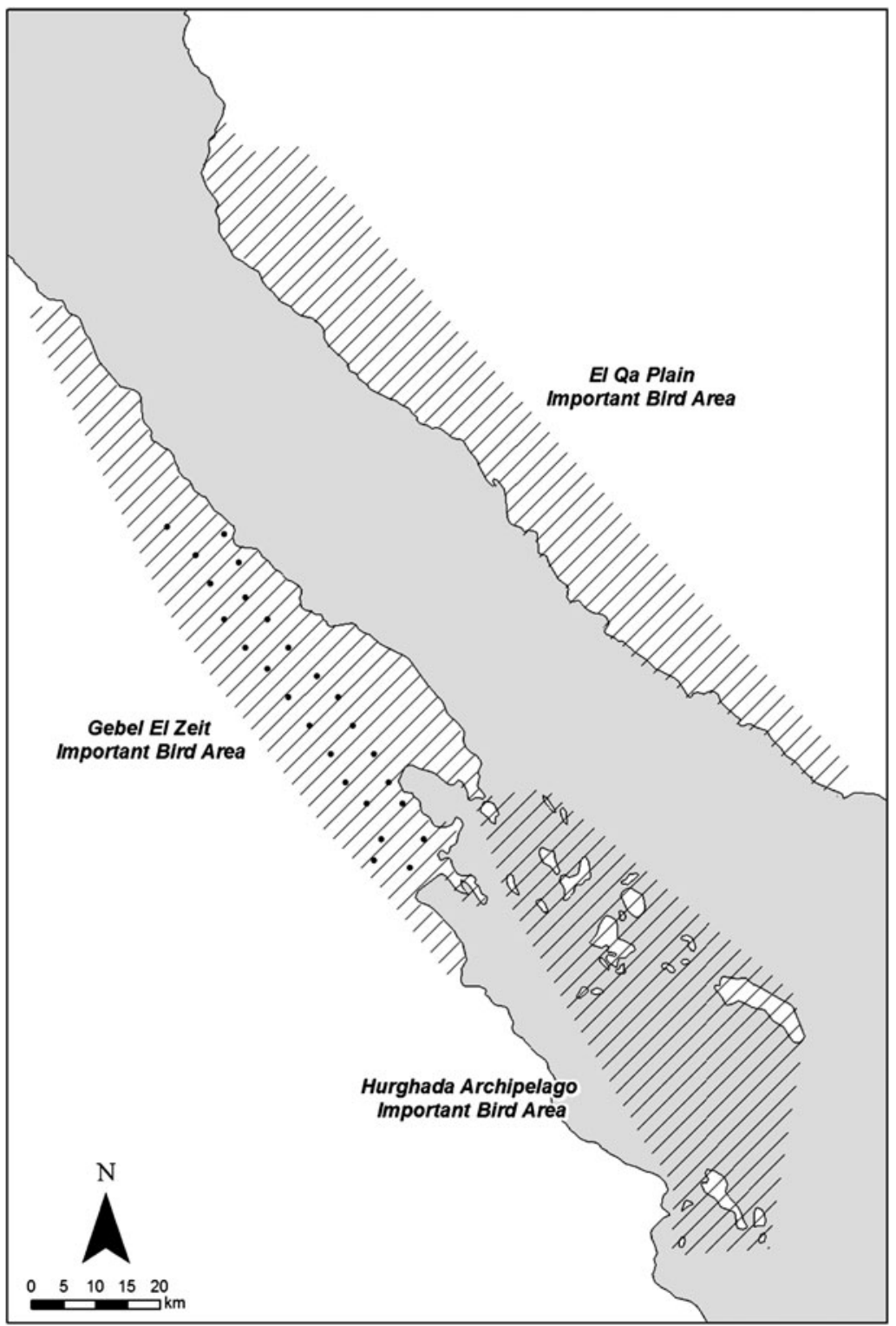

Figure 1. Boundaries of the Gebel el Zeit, Hurghada Archipelago and El Qa Plain Important Bird Areas, together with points surveyed in Hilgerloh (2009). 